\title{
SOSIALISASI SANITASI DIRI DAN LINGKUNGAN DI PESANTREN SALAFI MELALUI POS KESEHATAN PESANTREN (POSKESTREN) DALAM MEMBENTUK SIKAP SANTRI TERHADAP SANITASI
}

\author{
Uud Wahyudin \& Hadi Suprapto Arifin \\ Program Studi Ilmu Komunikasi, Fakultas Ilmu Komunikasi, Universitas Padjadjaran
}

\begin{abstract}
ABSTRAK
Berbagai perilaku hidup yang tidak bersih dan tidak sehat masih dapat dijumpai di pesantren-pesantren salafi/ tradisional di perdesaan. Berdasarkan hasil penelitian dapat diketahui bahwa budaya hidup sehat di pondok pesantren salafi tidak memenuhi pola hidup sehat. Hal ini dapat dilihat pada indikasi kesehatan yaitu santri dalam menjaga kebersihan dan kesehatan lingkungan sekitar kurang sehat karena masih banyak kekurangan seperti terlalu banyak jumlah santri yang menyebabkan kumuh dan berdesakan dan masih kurangnya ventilasi dalam kamar yang menyebabkan lembab. Hasil penelitian juga menunjukkan bahwa sosialisasi sanitasi diri dan lingkungan melalui poskestren berkaitan dengan inovasi, waktu, saluran, dan sistem sosial memberikan pengetahuan dan mengubah perilaku santri untuk menjaga kesehatan dan kebersihan lingkungan sekitar, membuat ventilasi yang cukup dalam kamar atau tempat tinggal, membudayakan pola perilaku hidup sehat dengan ditambah olahraga senam, jogging dan lainnya, mengkonsumsi air yang matang, istirahat dengan cukup dan gunakan alas tidur dengan kasur atau karpet. Pos Kesehatan Pesantren (Poskestren) di pesantren salafi di perdesaan yang dilakukan secara terus menerus dengan cara mendekatkan akses pelayanan kesehatan berhubungan dengan upaya memberdayakan santri dalam bidang kesehatan diri dan lingkungannya. Kesimpulan penelitian bahwa poskestren di pesantren salafi yang terletak di kecamatan Jampang Tengah Kabupaten Sukabumi merupakan langkah pendekatan edukatif untuk mendampingi (memfasilitasi) santri di pesantren untuk menjalani proses pembelajaran yang berupa proses perubahan sikap positif dalam pemecahan masalah-masalah kesehatan (sanitasi diri dan lingkungan) yang dihadapinya.
\end{abstract}

Kata-kata kunci: Komunikasi kesehatan, sanitasi, poskestren, pesantren salafi

SOCIALIZATION OF SELF AND ENVIRONMENTAL SANITATION IN SALAFI ISLAMIC BOARDING SCHOOL THROUGH ISLAMIC BOARDING SCHOOL HEALTH POST (POSKESTREN) TO FORM THE SANTRI ATTITUDE TO SANITATION

\begin{abstract}
Various of unclean and unhealthy behaviors can still be found in pesantren salafi. Based on the results of this research, the culture of healthy living in salafi boarding school did not meet the required healthy lifestyle. This can be seen in the health indicator of students such as maintaining the clean and health environment is not satisfactorily enough because there are too many number of students who in the end cause dirtiness with the lack of ventilation in the room, which causes damp environment. Healthy lifestyle in boarding, sadly, due to several factors such as customs, and beliefs of students in defining health, cannot be fulfilled also show that the personal and environmental sanitation socialization through poskestren related to innovation, time, channel, and social systems, providing knowledge and changing in students behaviors on maintaining health and hygiene environment, such as making adequate ventilation in the room, developing patterns of healthy life behavior with gymnastics, jogging and consuming boiled water, and sufficient rest on a bed with a mattress pad or carpet. This study results conclude that the development of poskestren (Islamic Boarding School Health Post) in islamic boarding school located in the district of salafi Jampang Tengah Sukabumi, is an educative approach to facilitate students at the school in undergoing a learning process in the form of a positive attitude in the process of solving occuring health problems (personal and environmental sanitation).
\end{abstract}

Keywords: Health communication, sanitation, islamic boarding school health post, salafi islamic boarding school

Korespondensi: Drs. H. Hadi Suprapto Arifin, M.Si. Program Studi Ilmu Komunikasi, Fakultas Ilmu Komunikasi, Universitas Padjadjaran, Jl. Raya Bandung-Sumedang Km.21.Email: hsa_dalong@yahoo.com 


\section{PENDAHULUAN}

Berbagai perilaku hidup yang tidak bersih dan tidak sehat masih dapat dijumpai di pesantren-pesantren salafi/ tradisional di perdesaan. Berdasarkan observasi, di pesantren salafi/ tradisional di perdesaan di Kecamatan Jampang Tengah Kabupaten Sukabumi, penulis menemukan bahwa santri di Pondok Pesantren salafi/ tradisional biasanya tidur dengan cara meletakkan kasur di lantai sebagai tempat tidur mereka dan ada juga yang hanya sekadar memakai tikar saja. Sebelum melakukan kegiatan rutin, mereka membersihkan kasur dan alas tidur lainnya dengan cara menumpuk di pinggir ruangan kamar tidur. Pada kehidupan sehari-hari santri sering memakai baju dan handuk secara bergantian atau saling meminjam pakaian.

Selanjutnya, penelitian Isa Ma'rufi, dkk (2005) menemukan bahwa faktor sanitasi berperan dalam prevalensi penyakit scabies. Perilaku santri yang tidak saniter, seperti saling meminjam pakaian, menggunakan alat mandi bersama, serta tempat tidur yang berimpitan adalah penyebab menularnya penyakit scabies di pesantren. Perilaku yang tidak sehat yang lain adalah kamar tidur yang tidak saniter dan kurangnya pencahayaan. Hasil penelitian Rohmawati (2010: 3) menunjukkan bahwa perilaku hidup bersih, dengan adanya sanitasi lingkungan dan sanitasi perorangan yang baik berperan dalam memberantas penyakit scabies di pesantren. Sanitasi perorangan memegang peranan yang sangat penting. Mandi yang teratur, mencuci tangan sebelum makan, menggunakan lap tangan yang bersih, kebiasaan menggosok gigi sebelum tidur, mencuci pakaian dengan bersih dan teratur, menjemur handuk setelah dipakai, dan membersihkan tempat tidur adalah faktor sanitasi perorangan yang berperan dalam memberantas penyakit scabies di pesantren di Lamongan. Selanjutnya, penelitian ini juga menunjukkan bahwa sanitasi pesantren harus diperbaiki seperti membuat kamar mandi dan membuat sumur sendiri dibandingkan dengan memanfaatkan sungai untuk mandi, cuci, dan kakus.

Berdasarkan beberapa hasil penelitian di atas dapat diketahui bahwa budaya hidup sehat di pondok pesantren salafi tidak memenuhi pola hidup sehat. Hal ini dapat dilihat pada indikasi kesehatan yaitu santri dalam menjaga kebersihan dan kesehatan lingkungan sekitar kurang sehat karena masih banyak kekurangan seperti terlalu banyak jumlah santri yang menyebabkan lingkungan menjadi kumuh dan berdesakan serta masih kurangnya ventilasi di dalam kamar yang menyebabkan ruangan menjadi lembab. Gaya hidup di pesantren yang kurang sehat ini disebabkan beberapa faktor seperti kebiasaan dan kepercayaan santri dalam memaknai kesehatan.

Salah satu upaya yang dapat dilakukan adalah memberikan sosialisasi sanitasi diri dan lingkungan kepada santri untuk menjaga kesehatan dan kebersihan lingkungan sekitar, perlunya ventilasi yang cukup dalam kamar atau tempat tinggal, pentingnya perilaku hidup sehat dengan ditambah olahraga senam, jogging dan lainnya, mengkonsumsi air yang matang, istirahat dengan cukup dan gunakan alas tidur dengan kasur atau karpet. Kesehatan bagi santri di pesantren salafi di perdesaan perlu diperjuangkan secara terus menerus dengan cara mendekatkan akses pelayanan kesehatan dan memberdayakan kemampuan mereka. Melalui Pos Kesehatan Pesantren (Poskestren) inilah diharapkan dapat memberdayakan santri dalam bidang kesehatan diri dan lingkungannya.

Puskesmas Kecamatan Jampang Tengah sebagai pusat penggerak pemberdayaan kesehatan masyarakat untuk tahap awal mencoba mengembangkan langkah-langkah pendekatan edukatif di wilayah kerjanya. Upaya yang dilakukan diantaranya mendampingi (memfasilitasi) santri di pesantren untuk menjalani proses pembelajaran berupa pemecahan masalah kesehatan yang dihadapi melalui kegiatan pengembangan desa siaga yaitu mengembangkan poskestren di pesantren yang terletak di kecamatan Jampang Tengah kabupaten Sukabumi.

Bertitik tolak dari kecenderungan tersebut, permasalahan yang diteliti dapat dirumuskan sebagai berikut: "Bagaimanakah Sosialisasi Sanitasi Diri dan Lingkungan di Pesantren Melalui Poskestren dalam Membentuk Sikap Positif Santri terhadap Sanitasi?"

Berdasarkan rumusan masalah di atas, maka tujuan penelitian ini adalah (1) Untuk mengetahui inovasi Poskestren dalam membentuk sikap positif santri terhadap 
sanitasi di pesantren salafi perdesaan. (2) Untuk mengetahui saluran komunikasi Poskestren dalam membentuk sikap positif santri terhadap sanitasi di pesantren salafi perdesaan. (3) Untuk mengetahui sistem sosial Poskestren dalam membentuk sikap positif santri terhadap sanitasi di pesantren salafi perdesaan dan (4) Untuk mengetahui pemanfaatan waktu Poskestren dalam membentuk sikap positif santri terhadap sanitasi di pesantren salafi perdesaan.

\section{METODE PENELITIAN}

Penelitian ini dirancang dengan menggunakan metode penelitian survei yang bersifat penelitian penjelasan (explanatory research), yakni penelitian untuk menjelaskan hubungan antarvariabel melalui pengujian hipotesis (Singarimbun, 1989: 5). Sebelum dilakukan analisis hubungan antarvariabel penelitian, terlebih dahulu dilakukan deskripsi data yang berhubungan dengan variabel penelitian. Oleh karena itu, rancangan penelitian yang digunakan, menurut Van Dalen (Rakhmat, 1991: 7), dapat juga disebut penelitian survei yang bersifat deskriptif korelasional.

Dari sejumlah santri peserta aktif sosialisasi sanitasi di pesantren salafi di Kecamatan Jampang Tengah Kabupaten Sukabumi, diambil santri sebagai peserta sosialisasi yang aktif sebanyak 3 (tiga) kali pertemuan. Sampel yang diambil dari satu pesantren adalah 20 santri. Dari tiga pesantren desa diambil santri yang aktif mengikuti sosialisasi ( 3 × $20=60$ santri). Dari masing-masing pesantren yang terpilih secara random, maka seluruh santri/ peserta sosialisasi yang berada di pesantren itu adalah sampel penelitian. Adapun bagan penelitiannya dapat dilihat pada gambar di halaman berikut.

\section{HASIL DAN PEMBAHASAN}

Bagian ini mengemukakan hasil penelitian dan pembahasan dari pengolahan data primer yang diperoleh yaitu data yang diperoleh dari responden melalui angket yang disebarkan pada 60 responden. Variabel kegiatan sosialisasi sanitasi poskestren dibagi dalam 4 bagian subvariabel yaitu inovasi, saluran komunikasi, waktu, dan sistem sosial.

Kegiatan sosialisasi sanitasi diri dan lingkungan melalui poskestren sudah dilakukan secara periodik. Pengasuh pondok pesantren sudah memanfaatkan poskestren untuk mensosialisasikan pengetahuan kesehatan kepada para santri baik yang diajarkan dalam kitab melalui kegiatan belajar mengajar maupun dengan cara mengundang bidan, dokter atau dinas kesehatan setempat melalui pertemuan untuk menambah wawasan santri mengenai hidup sehat.

Salah satu upaya yang dilakukan adalah memberikan sosialisasi sanitasi diri dan lingkungan kepada santri untuk menjaga kesehatan dan kebersihan lingkungan sekitar, berikan ventilasi yang cukup dalam kamar atau tempat tinggal, budayakan pola perilaku hidup sehat dengan ditambah olahraga senam, jogging dan lainnya, mengkonsumsi air yang matang, istirahat dengan cukup dan gunakan alas tidur dengan kasur atau karpet. Kesehatan bagi santri di pesantren salafi di perdesaan perlu diperjuangkan secara terus menerus dengan cara mendekatkan akses pelayanan kesehatan dan memberdayakan kemampuan mereka. Melalui Pos Kesehatan Pesantren (Poskestren) inilah diharapkan dapat memberdayakan santri dalam bidang kesehatan diri dan lingkungannya.

Inovasi; gagasan, tindakan, atau barang yang dianggap baru oleh seseorang. Dalam hal ini, kebaruan inovasi diukur secara subjektif menurut pandangan individu yang menerimanya. Jika suatu ide dianggap baru oleh seseorang maka ia adalah inovasi untuk orang itu. Konsep 'baru' dalam ide yang inovatif tidak harus baru sama sekali (Rogers, 1987: 25).

Pesantren dengan dipimpin kyai atau ulama agama sering bertindak sebagai pemimpin pendapat (opinion leader) mengenai ideide pembangunan bagi para pengikutnya. Beberapa pemimpin pendapat biasa mengambil prakarsa dalam komunikasi dengan mencari kesempatankesempatan untuk menyebarluaskan pesanpesannya (Depari dan Andrews, 1978: 23).

Dalam proses sosialisasi diperlukan berbagai sarana dan media untuk menjadikan tempat berkomunikasi dan berinteraksi sehingga timbulah hubungan timbal balik yang dapat memperlancar proses sosialisasi, seperti sekolah, keluarga, lingkungan kerja, dan media massa. 


\section{PERSPEKTIF PSIKOLOGI BEHAVIORISME}

Manusin dipandang sebagai mahluk pasif (Homo mechamichas)

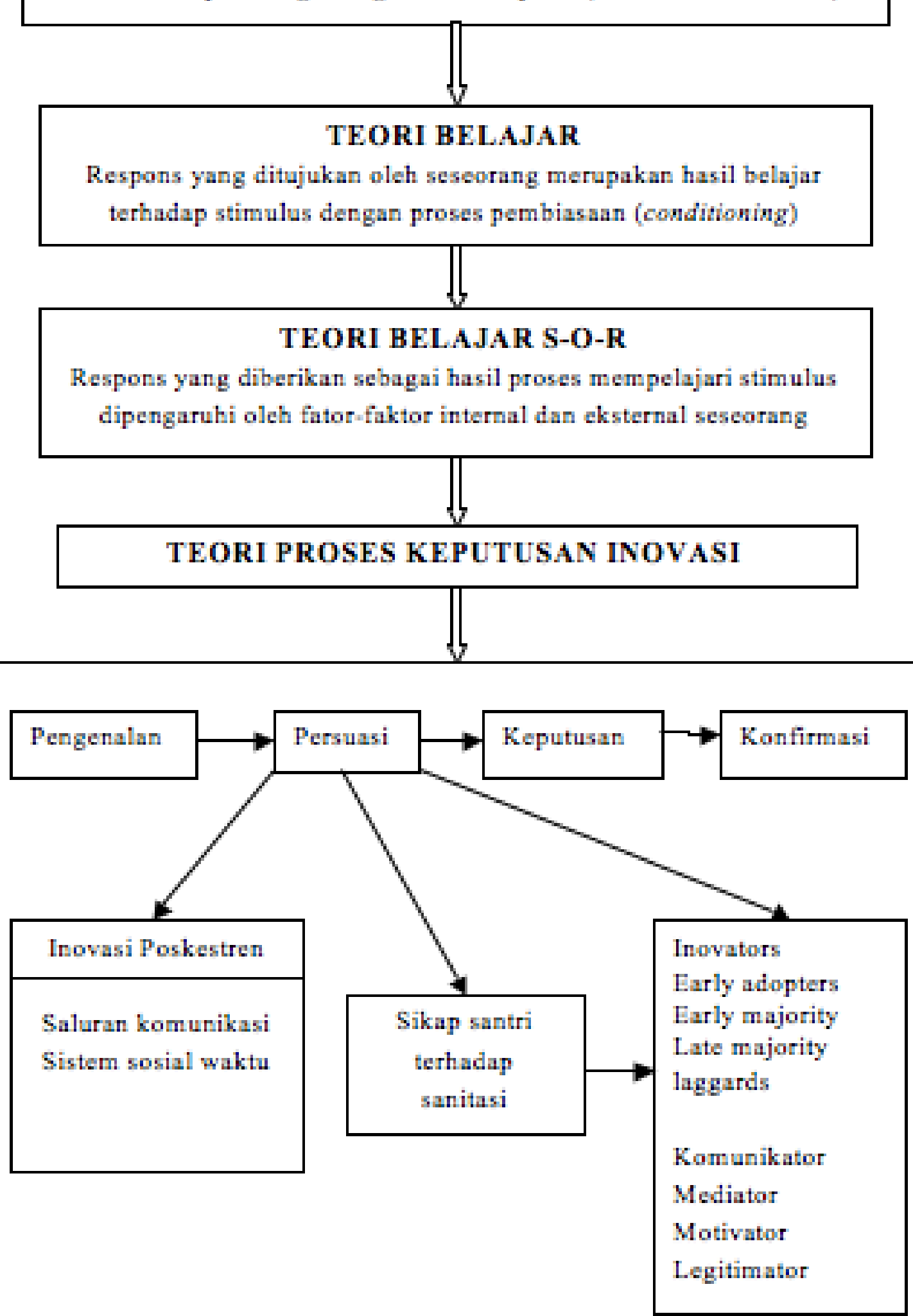


Waktu yang diperlukan dalam proses keputusan inovasi di pesantren berkaitan dengan sanitasi diri dan lingkungan melalui poskestren tidak memerlukan waktu yang lama. Hal ini disebabkan santri lebih mudah memahami tentang manfaat poskestren bagi kesehatan diri dan lingkungan pesantren. Dengan alasan tersebut maka sosialisasi program kesehatan sanitasi diri dan lingkungan melalui poskestren bagi santri di pesantren salafi di Desa Jampang Tengah Sukabumi harus dilaksanakan secara intensif untuk menanamkan sikap positif terhadap sanitasi.

Pesantren sebagai sebuah sistem sosial yang memiliki elemen: kyai, ustaz, santri, masjid, dan kitab kuning lebih cepat menerima informasi tentang kesehatan berkaitan dengan sanitasi diri dan lingkungannya melalui poskestren. Hal ini disebabkan pesantren memiliki sistem kesehatan Islami yang sebelumnya sudah menjadi budaya dalam kehidupan pesantren. Sehingga dengan masuknya poskestren yang memberikan berbagai informasi kesehatan islami menjadi bahan informasi tambahan untuk membuat pesantren menjadi lebih sehat, tentunya masih dalam koridor budaya Islam (Ziemek, 1986: 194-195).

Sosialisasi sanitasi diri dan lingkungan melalui poskestren ada dalam kategori tinggi. Artinya, sosialisasi memberikan pengetahuan tentang sanitasi diri dan lingkungan bagi santri. Sanitasi juga membentuk rasa suka atau senang terhadap kebersihan diri dan lingkungan pesantren. Selanjutnya, sosialisasi membuat santri menjadi lebih giat untuk melaksanakan kerjasama dalam menjaga kebersihan diri dan lingkungan pesantren di mana mereka tinggal dan belajar.

Atensi santri terhadap sanitasi diri dan lingkungannya sangat tinggi dan mereka lebih cepat menerima informasi kesehatan yang disampaikan melalui poskestren terutama yang berkaitan dengan sanitasi diri dan lingkungan. Mereka cepat mengubah beberapa kebiasaan mereka yang tadinya tidak bersih dan tidak sehat menjadi sebuah sikap yang tinggi terhadap kebersihan dan kesehatan.

Dikaitkan dengan program Pembangunan Kesehatan Masyarakat Desa (PKMD) bahwa poskestren sebagai salah satu kegiatan promosi kesehatan adalah proses memberdayakan/ memandirikan masyarakat untuk memelihara, meningkatkan dan melindungi kesehatannya melalui peningkatan kesadaran, kemauan dan kemampuan, serta pengembangan lingkungan sehat. Dengan demikian, poskestren melalui program sanitasi diri dan lingkungan lebih mudah diterima dan diterapkan oleh para santri di pesantren salafi di perdesaan.

Puskesmas Kecamatan Jampang Tengah sebagai pusat penggerak pemberdayaan kesehatan masyarakat untuk tahap awal mencoba mengembangkan langkah-langkah pendekatan edukatif di wilayah kerjanya. Upaya yang dilakukan diantaranya mendampingi (memfasilitasi) santri di pesantren untuk menjalani proses pembelajaran berupa pemecahan masalah kesehatan yang dihadapi melalui kegiatan pengembangan desa siaga yaitu mengembangkan poskestren di pesantren yang terletak di kecamatan Jampang Tengah kabupaten Sukabumi.

Suksesnya suatu program dalam hal ini sosialisasi sanitasi melalui poskestren tergantung pada aktif atau tidak aktifnya partisipasi santri untuk menyukseskan program tersebut. Sehingga dalam posisi ini peran aktif santri di pesantren sangat penting artinya bagi kelancaran dan keberhasilan program poskestren tersebut dan tercapainya tujuan secara mantap. Sosialisasi sanitasi diri dan lingkungan melalui poskestren dicanangkan dalam rangka usaha pemerintah untuk menyebarluaskan program PHBS di Jawa Barat yang berkualitas. Pada dasarnya pemerintah daerah/ dinas kesehatan berkeinginan untuk membuat perubahan dari suatu kondisi tertentu ke keadaan lain yang lebih bernilai.

Dalam kegiatan sosialisasi sanitasi diri dan lingkungan melalui poskestren, banyak komponen atau elemen yang terlibat baik secara langsung maupun tidak langsung. Pada dasarnya, pesantren di perdesaan siap dalam melaksanakan program poskestren yang telah menjadi program pemerintah. Para santri berperan serta dalam mengikuti kegiatan sosialisasi sanitasi diri dan lingkungan melalui poskestren. Berdasarkan pengamatan langsung, tampaknya ketercapaian tujuan program sosialisasi sanitasi diri dan lingkungan tersebut masih perlu dijadikan perhatian mengingat 
masih lemahnya kontrol program terpadu ini di tingkat kecamatan atau tingkat yang paling bawah, yakni santri di pesantren pedesaan.

Promosi kesehatan mencakup upaya untuk memotivasi, mendorong dan membangkitkan kesadaran akan potensi yang dimiliki masyarakat, agar mereka mampu memelihara dan meningkatkan kesehatannya. Di samping itu promosi kesehatan juga mencakup berbagai aspek khususnya yang berkaitan dengan aspek sosial budaya, pendidikan, ekonomi dan pertahanan keamanan sesuai dengan konsep promosi kesehatan, individu dan masyarakat bukan hanya menjadi objek yang pasif (sasaran) tetapi juga subjek (pelaku). Dengan demikian, sebenarnya poskestren menjadi salah satu upaya mendorong dan meningkatkan kesehatan santri di pesantren dengan santri sendirilah yang menjadi pelaku utama terciptanya gaya hidup dan lingkungan yang sehat mereka.

\section{SIMPULAN}

Terdapat hubungan yang signifikan dengan arah hubungan yang positif antara inovasi sosialisasi sanitasi diri dan lingkungan melalui poskestren dengan sikap santri terhadap sanitasi. Terdapat hubungan yang signifikan dengan arah hubungan yang positif antara dimensi saluran komunikasi sosialisasi sanitasi diri dan lingkungan melalui poskestren dengan dengan sikap santri terhadap sanitasi. Terdapat hubungan yang signifikan dengan arah hubungan yang positif antara dimensi waktu sosialisasi sanitasi diri dan lingkungan dengan sikap santri terhadap sanitasi. Terdapat hubungan yang signifikan dengan arah hubungan yang positif antara dimensi sistem sosial sosialisasi sanitasi diri dan lingkungan dengan sikap santri terhadap sanitasi.

Saran yang peneliti berikan dalam penelitian ini yaitu sebaiknya sosialisasi kesehatan di pesantren salafi di perdesaan lebih banyak dilakukan tidak hanya di pesantren salafi perdesaan tetapi juga di pesantren di perkotaan dengan memanfaatkan poskestren sebagai saluran komunikasi yang memudahkan penyampaian pesan kesehatan bagi santri. Selain itu, penelitian dengan topik sanitasi diri dan lingkungan di pesantren semoga dapat pula dilakukan di wilayah yang lebih luas dengan menggunakan metode dan pendekatan berbeda.

\section{DAFTAR PUSTAKA}

Depari, E., \& McAndrews, C. (1978). Peranan komunikasi massa dalam pembangunan . Yogyakarta: Gajah Mada University Press.

Detels \& Bealeghole. (2002). Text of public health. Oxford.

Dinas Kesehatan Propinsi Jawa Barat. (2003). Profil kesehatan. Bandung: Dinkes Jabar.

Liliweri, A. (2008). Dasar-dasar komunikasi kesehatan. Pustaka Pelajar. Yogyakarta.

Rakhmat, J. (1991). Metode penelitian komunikasi. Bandung: Remaja Rosdakarya.

Rogers, E. M.(1987). Memasyarakatkan ide-ide baru. (disarikan oleh Abdillah Hanafi). Surabaya: Usaha Nasional.

Singarimbun, M. (1989). Metode penelitian survei. Jakarta: LP3ES.

Tjondronegoro, S.M.P. (1978). Modernisasi Pedesaan: Pilihan Strategi Dasar Menuju Lepas Landas. Prisma No. 3/ Tahun VII-April 1978.

Ma'rufi, I. (2005). Faktor Sanitasi Lingkungan yang Berperan terhadap Prevalensi Penyakit Scabies di Pesantren di Kabupaten Lamongan. Jurnal Kesehatan Lingkungan Universitas Airlangga, Vol 2 No.1. Juli 2005.

Pedoman Perilaku Hidup Bersih dan Sehat Jawa Tengah, (2003).

Rohmawati. (2010). Penyakit scabies di pesantren. Medan: Pascasarjana Universitas Sumatera Utara.

Schiavo, R. (2007). Health communication. San Francisco: John Wiley\&Sons, Inc.

Ziemek, M.(1986). Pesantren dalam perubahan Sosial. Jakarta: P3M. 